\title{
The car free city model
}

\author{
M. Alameri \\ Urban Planning and Design, Masdar City, Abu Dhabi, UAE
}

\begin{abstract}
The great challenge emerging in sustainable developments around the world is to marry new transportation systems of conceiving cities, in line with the principles of quality and functionality of the transportation needs. Once the principles of quality of space and of functional requirements of the transportation system are evenly balanced, Man's dependency on the car becomes questionable and how it is addressed in the urban fabric. The aim of this paper is identifying the urban fabric looking for a direct relation between human beings and the urban spaces rather than a man-car-space relation, where the car stands between man and the living space.

The Masdar project is one of the first attempts to create a modern urbanized area of these dimensions that is completely free of privately-owned vehicles. Innovative and revolutionary in its principles, it follows a pragmatic approach to the issues related to cultural, technological and economical feasibility - enabling Masdar to become reality and a model for future sustainable urban developments based on a renewed relationship between man and urban spaces. The city has the opportunity to operate on a model that reduces carbon dioxide emissions, noxious gases, and provides a safer pedestrian and human friendly environment while reducing resident carbon footprints which contribute to global warming.
\end{abstract} Keywords: Masdar, car-free city, integrated transport, sustainability, innovation, new urbanism, master planning.

\section{Introduction}

This paper explains how Masdar City has been designed as a car-free city. It shows how master planning and transportation planning have come together to deliver a sustainable integrated city where a projected 40,000 residents and 50,000 employees can live in an enhanced environment, free from the everyday traffic impact experienced by so many dwellers in traditional cities. 


\section{New urbanism}

\subsection{New urbanism}

New Urbanism has a role in freeing people from automobile-dependence and in reversing development patterns that threaten our global climate.

\subsection{Making urbanism legal again}

Although compact, mixed-use urban form achieved such value before 1950, separate-use zoning codes and high-volume road standards subsequently helped to make sprawl (Figure 1) today's default development option. New Urbanists are providing leaders with tools (and more tools) to reverse course and strengthen the character, livability, and diversity of their communities.

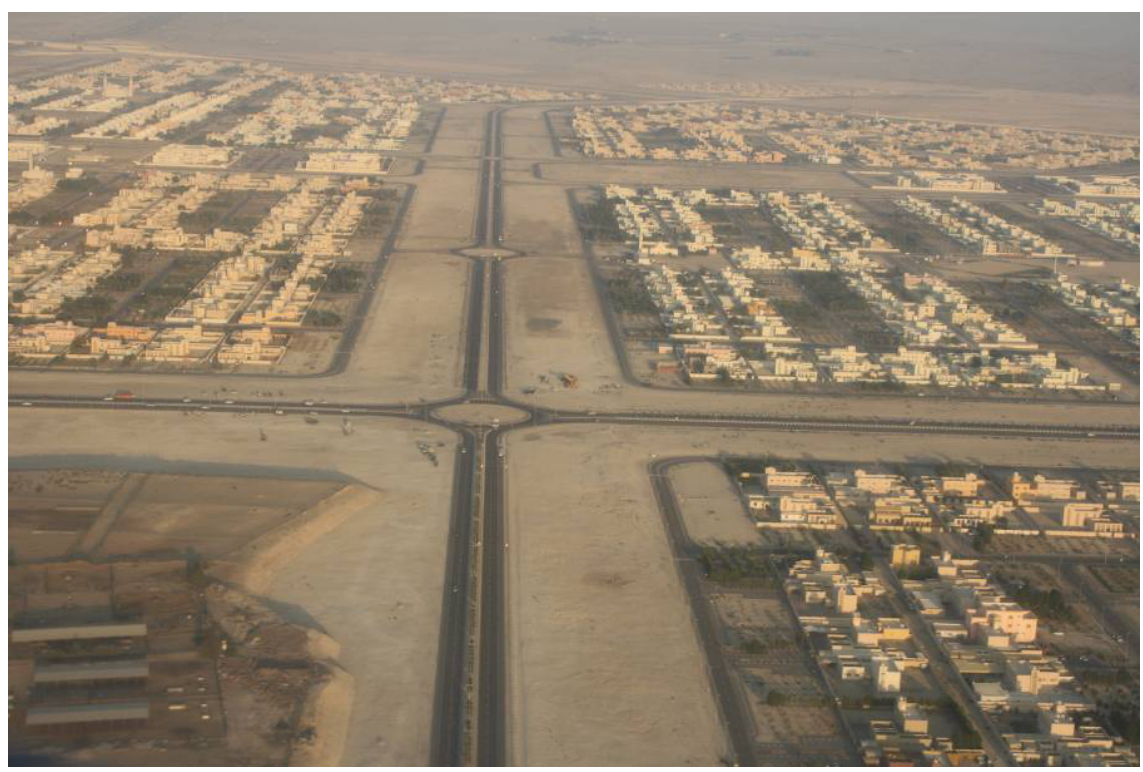

Figure 1: Urban sprawl.

\subsection{Creating enduring neighborhoods}

A growing movement, New Urbanism recognizes walkable, human-scaled neighborhoods as the building blocks of sustainable communities and regions. The Charter of the New Urbanism (CNU) articulates the movement's principles and defines the essential qualities of urban places from the scale of the region to the individual building. 


\subsection{Celebrating shared spaces}

New Urbanism makes shared space the organizing element of a community. Architecture physically defines streets as places of shared use. Care for the public realm adds character, builds value, promotes security, and helps residents feel proud of their community. Plazas, squares, sidewalks, cafes, and porches provide rich settings for interaction and public life.

\subsection{Making connections a priority}

Through grids of streets, transportation choices, and the siting of buildings along the sidewalks of compact blocks, New Urbanism brings destinations within reach and allows for frequent encounters between citizens, in sharp contrast to sprawl. A key measure of connectivity is how accessible communities are to people with a range of physical abilities and financial resources.

\subsection{Achieving sustainability: from building to region}

By focusing development, New Urbanism promotes efficient use of infrastructure and preservation of habitats and farmland. With green building leaders, $\mathrm{CNU}$ is establishing new standards for green design at the neighborhood scale. Transportation plays a pivotal role in sustainability and truly efficient transportation - walking, bicycling, and transit use is possible only where there is compact, urban form.

\subsection{Reclaiming urban places once thought lost}

New Urbanism is repairing the damage done to our cities through environmental degradation, misguided infrastructure projects and designs that isolated the poor. Through the United States Department of Housing and Urban Development's Hope VI program, new Urbanists have transformed deteriorating public housing into liveable mixed-income neighborhoods. And in numerous cities, CNU is helping to replace blighting freeways with neighborhood-friendly boulevards.

\section{Masdar}

\subsection{Masdar's location and context}

Masdar's development site of approximately 640 hectares supports sustainable planning considerations in terms its strategic location adjacent to the principal urban and regional transport infrastructure of Abu Dhabi. It is located between the principal access roads, Airport Road and Abu Dhabi-Dubai Road, linking Abu Dhabi to the airport, to Dubai and beyond (Figure 2). Further, its immediate adjacency to the international airport gives the Masdar development significant potential to become a strategic and emblematic gateway into Abu Dhabi. As such, the Masdar development has the capacity to be the first and parting 


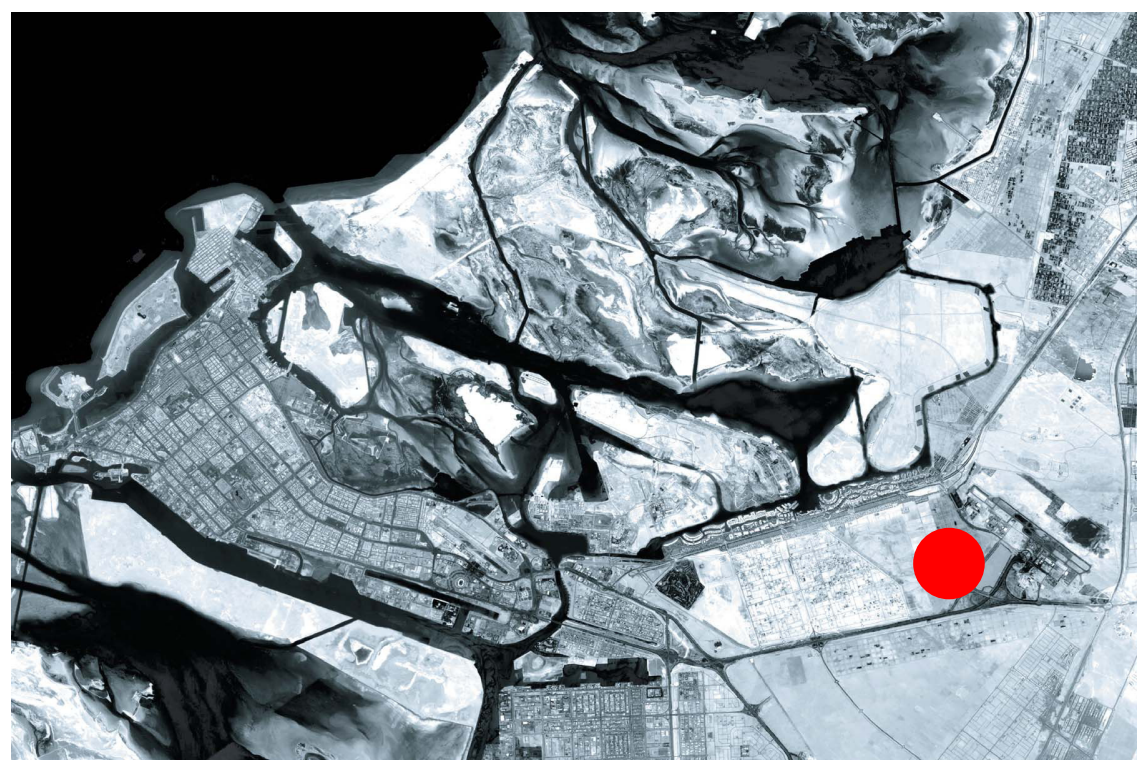

Figure 2: Masdar's location.

emblem of Abu Dhabi's sustainable development and environmentally sensitive socio-economic growth.

Its proximity to the airport is also a vital link in attracting world partners. Within the global community ease of access for businesses, visiting specialists, and guest lecturers alike ensure the Masdar development is tied in with the expanding economy. It would be a mistake to outpost this centre of research. Its success relies upon being embraced within the centre of the new developments as a living example of a successful community aiming for a zero carbon emission lifestyle.

The environment immediately surrounding the site is to showcase various ambitious urban development projects in the future, including the expansion of the airport to provide a second runway and a new high capacity passenger terminal, developments of Al Raha Beach and Al Raha Gardens to the northwest and the development of 10 Towers immediately north of the site. Over the coming years, these development initiatives will establish a community to complement and invigorate the Research and Development community that it is envisaged will engage with the facilities and opportunities on the Masdar site. The Light Rapid Transit (LRT) system will link Masdar to the Al Raha Beach development and the wider area.

The proximity of the Al Raha projects, Khalifa City and Yas Island means that a large proportion of the population can commute from these areas to Masdar via the LRT without using cars.

By creating a balanced mix of uses it is possible to achieve a good quality of life by integrating the commercial, research and educational areas with the more community based areas. A compact, pedestrian friendly urban form complements 
work and living. It will be possible to walk or cycle anywhere within the city and its environs, and these modes will be appropriate for most trips within the city most of the time. It is this focus on providing a range of alternatives to the car, both inside and outside the city, which seeks to minimise carbon emissions from transport in the Masdar community.

\subsection{Issues that influence life in urban neighborhoods}

According to a study into "Density and Urban Neighborhoods in London" [1], carried out by the London School of Economics and Political Science, good access to public transport has the single highest rank for the people in the sample neighborhoods. Masdar responds to this desire by providing a fully integrated public transport system. One of Masdar's aims is to provide a test-bed for innovative concepts and systems, and this is demonstrated through the complete integration of walking and cycling with five public transport systems within and outside the city:

- the novel automated driverless PRT system linking Masdar Institute to its car park [2]

- the orbital Group Rapid Transit (GRT) system that circles the city's centre providing easy access to wide areas of the city

- the LRT through the city providing access from outside and distribution within Masdar along the spine of the city

- the Metro that will provide a direct service into Masdar from Abu Dhabi's CBD and other parts of Abu Dhabi city

- the point-to-point premium service using electrically powered E-taxis for direct travel in the city for those who cannot or do not want to use the other systems.

This integration seeks to introduce a new age of public transport provision that offers a safe and clean way of reaching your destination.

The PRT pilot project links Masdar Institute with its car parking at the edge of the city, providing a quick, easy and safe way of travel, either as individuals or in small groups.

Ranking second is the provision of local facilities, ranging from health services (mentioned by a third of the respondents) to retail and educational

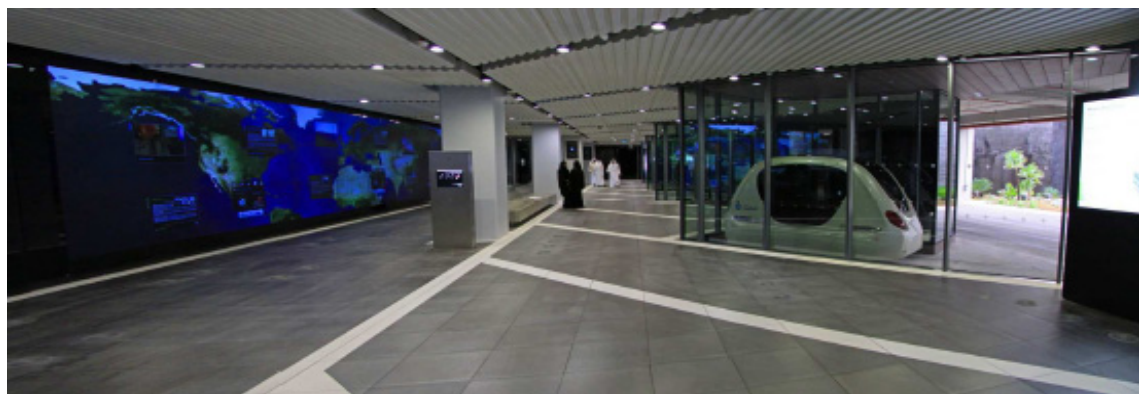

Figure 3: $\quad$ Northern car park PRT station at Masdar city. 
facilities, leisure and activity facilities and places for community activities. In Masdar, all of those will be provided - decentralized across the city - to improve accessibility for all the residents of Masdar.

In the summary category of the environment (ranking third), general appearance and parks/open spaces are mentioned most often. Whereas the first is a question of both building quality, management and maintenance, the provision of parks and open spaces is a key element of the master plan: Masdar offers with the green fingers and public squares more than $6.5 \mathrm{~m}^{2}$ of public open space for each resident (compared to roughly $2.5 \mathrm{~m}^{2}$ for an area such as Pimlico in London). This is supplemented by all the semi private courtyards and private balconies.

\subsection{Masdar: the car free city}

JH Crawford, in his book 'Carfree Cities', says "Transport is vital to cities: no city can function without its passenger and freight transport system. As large cities based on car and truck transport gridlock, it has become apparent that a better solution is needed" [3]. The Masdar project is one of the first attempts to create a modern urbanized area of these dimensions that is completely free of privately-owned cars. The Masdar project represents a milestone for the future of sustainability in transport proposing a prototypical and sustainable "built environment" where residents and commuters can live, work, move and recreate without the need to own and drive a vehicle, essentially, a "car free" environment. Without the need for personal vehicles, the city has the opportunity to operate internally on a model that minimises carbon dioxide emissions and noxious gases, and provides a safer pedestrian and human friendly environment while reducing resident carbon footprints which contribute to global warming.

The principle driving the transportation strategy is designing a city around people's needs and not around the needs of cars as many modern cities do. This enhances walking as the primary mode of movement and also creates a humanfriendly and safe environment. The principles of quality of space and of functional requirements of the transportation system have been evenly balanced through the use of citywide shared space, where pedestrians, cyclists, GRT, Etaxis and delivery and servicing vehicles will co-exist on an equal basis.

The great challenge of this project is to marry this new way of conceiving cities, in line with the principles of quality and functionality of the transportation needs required by our contemporary society. It was necessary to conceive an innovative system of transport capable of meeting these aims as a substitute for the car. The project - innovative and revolutionary in its principles - follows a pragmatic approach to issues related to cultural, technological and economical feasibility enabling Masdar to become reality and a model for future sustainable urban developments, based on a renewed relationship between man and urban spaces.

\subsubsection{Transportation principles}

In developing all the mobility and transportation elements the primary target is to embody the vision of the Masdar project to further the use and development of 
emerging clean technologies, to create a carbon-neutral internal transportation system and to enhance the overall sustainability of the project.

The internal mobility strategy is based on enhancing pedestrian mobility as the primary mode of transport for internal movements within Masdar.

It has been decided to ban the entrance of all private vehicles to Masdar, and to replace them with an emissions-free and carbon-neutral transport system that provides residents, employees and visitors with a level of service as close to that of a private car as possible. In terms of external accessibility, our studies aim to maximize the level of accessibility of the site while minimizing the impact of new road infrastructure on the surroundings. The primary targets in developing the mobility strategy were the following:

- Create an emission-free internal passenger network

- Minimize the surface occupied by transport inside the city

- Guarantee high levels of accessibility of the city

- $\quad$ Provide quick and efficient internal modes of transport that are fully integrated in time and space

- Ensure safe and secure modes are available 24/7 to all residents and commuters

- Provide full access to transportation systems within a short walking distance

- Enhance the development of the Abu Dhabi public transport network

- Enhance accessibility to the site by public transport

- Reduce car traffic

- Reduce the car-use and ownership ratio of the Masdar resident population

- Reduce pollutant emissions to access the site by switching some car trips to the LRT and Metro

- Minimize the external road infrastructure and car parks

- Provide an expansion-ready and technology upgradeable approach to implementation

- Provide a sustainable system that serves the users' needs fully

- Provide a system that strongly reflects healthy living lifestyles.

\subsubsection{Reducing emissions outside Masdar}

The City needs transport to bring visitors in, to take commuters to their workplace and to let residents travel outside the city. It is needed to take goods to their destinations and to collect and remove waste.

It is not reasonable to think that a city aiming for carbon neutrality would rely on a transport system heavily dependent on fossil fuels. Clearly, the external transport system cannot easily be made carbon neutral in the near future: people are allowed to drive their private cars on Abu Dhabi public roads and Masdar has no power to enforce the use of non-polluting and carbon neutral cars. The aim therefore will be not to reach carbon neutrality outside Masdar, but for Masdar's travel to generate as little $\mathrm{CO}_{2}$ and pollutant emissions as possible, with as little energy consumption as is reasonably achievable within the current 
framework of regulations and available technology. Masdar's sustainable transport strategy will expand over the site boundaries and encourage people to travel to and from the city by means other than the car.

\subsubsection{Transport to and from Masdar}

Today Abu Dhabi's city and regional transport relies almost entirely on the use of cars. The Urban Planning Council's "Plan Abu Dhabi 2030" underlines the importance for the future of the city of implementing a public transport network to avoid future grid lock of the city's external road network. "Plan Abu Dhabi 2030" includes a high-speed rail system and a Metro network that form the backbone of the expansion areas of the city, together with an extensive network of light rail and bus lines functioning as local and inter-district connectors.

The DOT published its Surface Transport Master Plan in June 2009. Figure 4 illustrates the main features. This shows the first phase of the LRT network around Masdar being in place and operating in 2015. The second phase, due in 2020, will link Masdar to a much wider area of Abu Dhabi, including the CBD. The main Metro route, which is a loop from the CBD up Abu Dhabi Island to Masdar and the airport, returning to the CBD through Yas Island and Saddiyat Island, is planned to be completed by 2015 . These public transport services will provide excellent links to and from Masdar, making it very accessible without having to travel by car.

Masdar's accessibility strategy strongly relies on the presence and growth of public transport. In fact, to be fully sustainable, the project cannot rely only on a

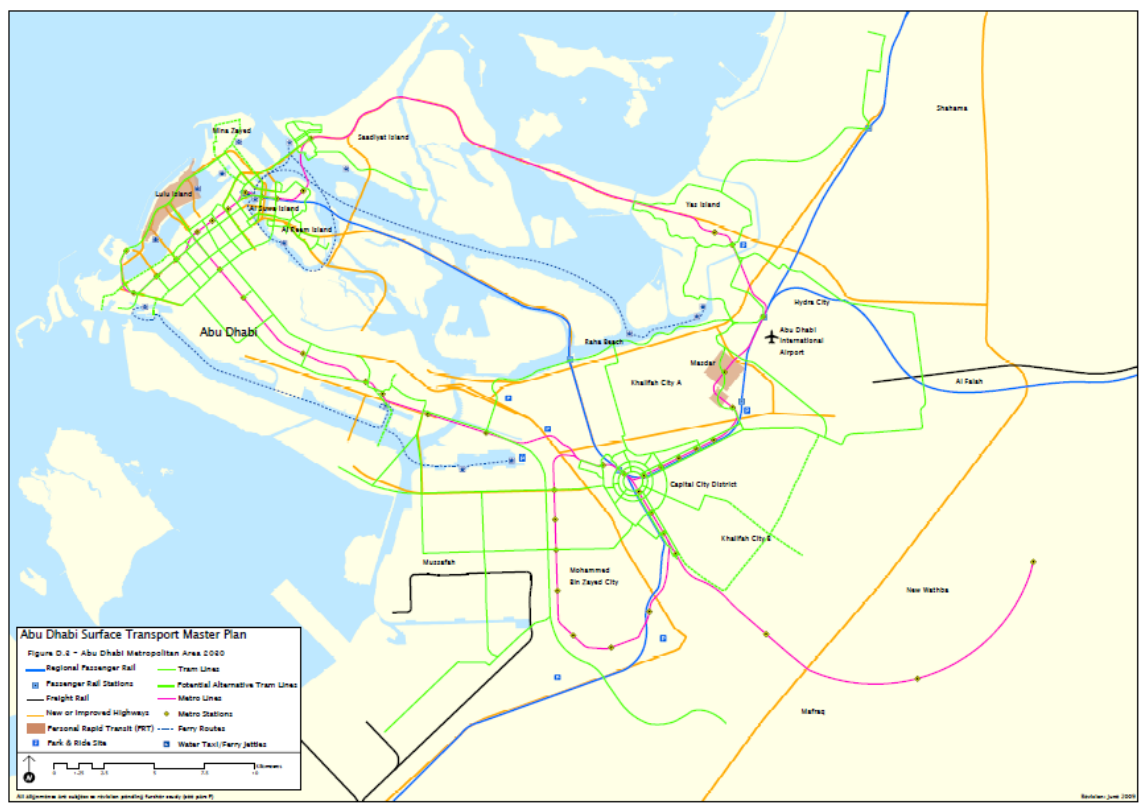

Figure 4: Abu Dhabi's surface transport master plan's transport networks. 
sustainable internal mobility strategy but also needs to be part of a general sustainable city planning approach. Once the master plan and the transportation network are fully developed, it is expected that at least a third of commuters and visitors will use public transport to access the site.

The systems related and interconnected to Masdar are:

- the HS rail stopping at the future Abu Dhabi Airport terminal. The intermodal station of the airport will be directly linked to Masdar with an express transport system. The airport's high accessibility will be exploited by Masdar, allowing as it does fast air access from everywhere in the world

- the Metro line connecting Masdar by way of a dedicated internal stop to all the relevant districts of the city planned expansion (Capital District, Gran Mosque District, Abu Dhabi CBD, Saadiyat Island and Yas Island)

- the Al Raha Beach LRT system is proposed to be extended from Al Raha into Masdar with four internal stops. The line will interconnect Masdar, Al Raha and the future Airport Terminal and represent a unique potential for Al Raha residents working in Masdar

- Further potential for improving future public transport includes modifying existing DOT bus routes that run near to or past Masdar. These routes currently provide what are essentially radial routes into and out of Abu Dhabi's CBD. Bringing them together in a new interchange a Masdar, linked to the LRT and indirectly to the Metro will have two effects. Firstly it will allow interchange between the existing bus routes that is not possible at the moment, providing new links between the communities served by these routes. Secondly, it will link Masdar to these communities, and will provide an option for people to travel between Masdar and these communities by a mode of travel more sustainable than the car.

\subsubsection{Vehicular accessibility}

The E-10 to the north of the site and the Airport Road to the south represent the major infrastructure for accessing the site. Two junctions from the E-10 and the existing airport junction in the south will provide access to Masdar. The vehicle flows will be distributed into a peripheral road network following the perimeter of the site on its eastern, southern and western boundary.

Roundabouts and traffic signal controlled junctions will link the external network to the internal one, providing access to the parking areas. External road improvements will be limited to the minimum necessary to mitigate for the impact of Masdar's predicted traffic, and will be evaluated in detail once a complete infrastructure layout is defined for the entire Airport District.

The generated vehicular traffic is largely dependent on the presence of the planned public transportation network and on the success of the different mobility management strategies that will be implemented within the project. The mobility management strategies aim to reduce the vehicular traffic generated by Masdar and to distribute the peak hour traffic into a larger band of time. The 
following strategies are among those being considered as part of Masdar's overall mobility management strategy:

- Car pooling: promoting car pooling for Masdar commuters, shifting the average car occupancy from the first stage of 1.2 passengers per car to up to 1.6 at the final development stage.

- Dedicated bus services for commuters: the companies and industries within Masdar site will be encouraged to organize a private bus service dedicated to their employees in substitution of cars.

- Park pricing: free car parks encourage people to use their own cars. Appling pricing strategies for commuters' and visitors' car parks will help to reduce private car use, help to promote car pooling and help to balance the peak flows over a larger band of time.

- Work schedule management: given the wide range of activities in Masdar the different working schedules will be managed as a whole in order to distribute the peak-hour traffic.

- Car sharing has a great potential for the residents of Masdar. Having cars available for short-term hire on a very flexible basis will make it more possible for some residents to consider not owning a car, or at least not owning a second or subsequent car. Residents will tend to use car share more in the evenings and weekends, leaving the cars free for business use during weekdays for trips that cannot conveniently be made by public transport.

Comparing a worst-case scenario based on Abu Dhabi's standard mobility rates where approximately 40,000 vehicles would travel to and from Masdar in the morning peak hour we estimate that with the public transport networks operating and a range of mobility management measures in place, the number of vehicles travelling to and from Masdar in that period can be reduced to around 28,000 vehicles (best case scenario). Traffic flows in the afternoon and evening peak hours are predicted to be less.

\subsubsection{Car parks}

Two different typologies of car parks are planned in the master plan allowing a total parking provision of about 42,000 parking spaces. These will be available to residents, commuters and visitors.

Some car parks will be outside the city square, but within Masdar's development boundary. These park-\&-ride sites will be mainly for commuters and visitors, and will be linked to the city initially by Group Rapid Transit (GRT) services, and later by LRT once that starts operating. With four GRT/LRT stops inside the main city square, and most employment concentrated down this spine, most people will be dropped within a short walk of their destination.

Other car parks will be located around the four edges of the city. These will be principally for residents, who will be allocated parking space within a reasonable walking distance of their homes. The resident parking demand is based on one car space per dwelling unit, which represents a low vehicle ownership ratio that is suitable for the Masdar development. Car sharing will be used if necessary as a second car option. 


\section{Conclusions}

Masdar is setting standards for a new way of integrating master planning with transport planning to deliver a sustainable place in which people will want to live, work and enjoy themselves. While it will attract commuters from a wide area, many of these will be able to use the LRT and Metro systems that the Abu Dhabi Department of Transport is planning to provide, and will not need to use cars to commute. Use of the LRT and Metro is encouraged through promoting and integrating walking and public transport modes within the city with the external public transport networks, allowing seamless travel to the journey's end.

Masdar is intended not just as an integrated sustainable development, but also as an exemplar that will demonstrate, test and evaluate new ways of doing things, so these can be tested, evaluated and then adopted in other places where appropriate.

The key elements of the master planning are to provide an environment where shared space can operate are the orientation of the city, to allow morning and evening breezes to pass through, together with narrow, shaded streets, which deliver a micro-climate where the ambient temperature is perceived as being acceptable for walking for much of the year. The most sustainable form of transport is, of course, walking, and through this design process walking will be promoted as the preferred travel mode. The success of this has already been demonstrated in the first phase of Masdar Institute, which is now occupied.

The car-free city model developed for and in Masdar is possible because of the use of shared space throughout the city and the planned sustainable integrated transport inside and outside the city. This will be demonstrated through three main themes:

- The demonstration Personal Rapid Transport system, now operating, which provides driverless automatic cars for up to six people, taking them from a car park to the Masdar Institute along a segregated dedicated undercroft track;

- The introduction of shared space throughout the rest of the city. There will be no private cars within the city. Pedestrians and cyclists will share the streets with the public transport (GRT and point-to-point etaxis) and the servicing and delivery vehicles that have to reach every development plot in the city for the city to function. But by imposing a low speed limit across the city streets, conflict between vehicular and non-vehicular movement is minimised, and this will deliver an environment where people can move freely with powered vehicles; and

- Demonstrating how five different powered modes (PRT, GRT, e-taxis, LRT and Metro) can be integrated with walking and cycling to deliver a co-ordinated sustainable transport system for tomorrow's cities. 


\section{References}

[1] "Density and urban neighbourhoods in London"; Richard Burdett, Tony Travers, Darinka Czischke, Philipp Rode and Bruno Moser (2005). Enterprise LSE Cities, London, UK.

[2] "Masdar City: modelling PRT in a carbon neutral development"; Dario Menichetti and Tom van Vuren; PRT@LHR 2010, 21-23 September 2010, London

[3] "Carfree Cities"; JH Crawford (2000/2002). International Books 